Egyptian Journal of Aquatic Biology \& Fisheries

Zoology Department, Faculty of Science,

Ain Shams University, Cairo, Egypt.

ISSN $1110-6131$

Vol. 24(7): $287-306$ (2020)

www.ejabf.journals.ekb.eg

\title{
An Integrated Field Survey and Remote Sensing Approach for Marine Habitat Mapping Along Hurghada Coast, Red Sea, Egypt
}

\author{
Ahmed H. Abo Elenin ${ }^{1}$, Samy A. Saber ${ }^{2}$, Sameh B. El-Kafrawy ${ }^{3}$ and \\ Hussein A. El-Naggar ${ }^{2 *}$
}

1. Zoology Department, Faculty of Science, Al-Azhar University, Assiut, Egypt.

2. Zoology Department, Faculty of Science, Al-Azhar University, Cairo, Egypt.

3. Marine Sciences Department, National Authority for Remote Sensing and Space Sciences, Egypt.

*Corresponding author: hu_gar2000@azhar.edu.eg; hu_gar2000@yahoo.com

\section{ARTICLE INFO}

\section{Article History:}

Received: Aug. 26, 2020

Accepted: Oct. 22, 2020

Online: Oct. 25, 2020

Keywords:

Benthic Cover,

Coral Reef,

Seagrass,

Spectral Signature,

GIS,

Satellite Image

\section{ABSTRACT}

The present study was carried out to integrate remote sensing techniques with field data to assess and detect the surface and subsurface conditions and their effects on the marine habitats as well as building an institutional capability for accurate classification, monitoring, and assessment of coastal area activities. A field trip was done during December 2018 to collect data about marine habitats along the Hurghada coast, Red Sea. The spectral signatures for the different marine habitats were carried out by using an instrument of SVC Spectroradiometer Field selecting spots. The satellite images analyses and collection of field observations and samples were done to measuring the integration between them.

According to the present results, Hurghada shoreline is stable with no areas of natural erosion/accretions detected along the coast, but the processes of landfilling and dredging, in order to widen and extend the beaches to accommodate touristic expansion, were observed. Also, the anthropogenic activities had a significant negative influence on the water quality and the ecological conditions of the nearshore areas of Hurghada city. The coastal area of the National Institute of Oceanography and Fisheries (NIOF), Hurghada branch, is one of the most diverse marine habitats along the Red Sea. The main habitat in this area is the coral reef being interrupted by patches of sand and seagrass meadows. Astoundingly, the results of the spectral signature profiles investigation in the study area corresponded greatly to the field survey and habitat mapping by Geographical Information System (GIS) technique. Results of both the measurements of spectral reflectance and the field trip along the study site revealed the presence of four bottom types, four seagrasses species, four seaweeds, and sixteen species of coral reef.

The present study recommends carrying out further studies to establish a spectral library for the bottom benthos and different marine habitats along the Red Sea. Also, the criteria and standards governing the capture, storage, and usage of spectral reflectance libraries should be settled to assess the coral reef environment from airborne or satellite imagery.

\section{INTRODUCTION}

The Red Sea is a semi-enclosed tropical water body connected to the Indian Ocean.

The Red Sea is known as a most world spectacular sea. It has wonderful coastline, habitat 
diverse and extensive coral reefs communities that has natural beauty. Also, it is an important route for many shipping, especially oil tankers and another ships passing via Suez Canal. (Ibrahim et al., 2017, El-Damhougy et al., 2017a, 2017b; Metwally et al., 2020). Geologically, the Red Sea is an ocean, lying on the diverging edges of the African and Arabian tectonic plates, where it is a continuation of the Indian Ocean Ridge (Braithwaite, 1987). Climatically, the Red Sea is surrounded by hot and continental land masses, with very low annual rainfalls (Shaban et al., 2020).

Biodiversity is considered as a major biological parameter influencing on ecosystem structure and function (Farrag et al., 2019; Mansour et al., 2020). It is important to conserve the marine biodiversity for continues of human life (El-Naggar $\boldsymbol{e t}$ al., 2019; Zakaria and El-Naggar, 2019). Nowadays, the Red Sea is considered as a most important repository of the marine biodiversity in the planet. Its relative isolation led to appearance of exceptional sets of biodiversity and endemism (PERSGA, 2003; ElNaggar, 2020). The Red Sea comprises sandy shores, rocky shores, mangroves, coral reefs, lagoon and seagrasses, pelagic zones and deep benthic habitat. The Red Sea fauna and flora include: seaweeds, phytoplankton, zooplankton, fishes, turtles, dugongs, whales and dolphins (Head, 1987; El-Damhougy et al., 2019). The opening of Suez Canal in 1869, the northern part of the Red Sea connected with the Eastern Mediterranean Sea, caused an exchange and migration of the fauna and flora between Indian and Atlantic oceans (Zakaria et al., 2016, 2018a, 2018b). The Red Sea ecosystem face continues degeneration and further declines in their habitats quantity and quality, this due to the increasing of natural pressures and human impacts (El-Naggar et al., 2017; Mona et al., 2019).

Habitat mapping serve as a spatial exemplification to describe and classify the different habitat units (Valentine et al., 2005). The spatial mapping characteristics and habitats distribution have a vital importance for analysis and management of costal and marine environment (Hamel and Andrefouet, 2010; Coggan and Diesing, 2011). The maps of Benthic habitat could be created by using various geospatial methods (White and Fitzpatrick, 2007; Australia, 2012). Immediate developments of GIS and remote sensing techniques have enhanced the ability to describe of the seafloor and associated habitats (Williams et al., 2010; Brown et al., 2011).

Remote sensing technique is a beneficial complement in both optimal selection for sampling sites, and the mapping distribution of seabed life (Blakey et al., 2015; Zakaria et al., 2019). Previously, the satellite imagery was used for recognize benthic cover in shallow water of marine environment (Lucas and Goodman, 2014). Remote sensing technique obviously has a significant function in such methodologies, so it is require a comprehensive understanding for the spectral characteristics of species that can separate from substrate (Swift and Bower, 2003). Call et al. (2003) examined the integration between in-situ water column attenuation measurements, spectral signatures of species, Landsat TM and Geographic Information System (GIS) to distinguish reef substrates. 
Spectral signature is known as a variation of emittance or reflectance of the material with respect to its wavelengths (i.e., reflectance/emittance as a function of wavelength). A spectral signature plots all the variations of reflected EM radiation as a function of wavelengths. Most of the applications of remote sensing approach process the digital images for extract the spectral signatures at every pixel and utilize them to classify the images in groups of similar pixels (segmentation) using different approaches. The spectral signatures of coral reefs and related scenes are measured by using a coupled atmosphere-ocean discrete ordinates radiative transfer model. Actual measured reflectance spectra from field work are used as input data (Lubin et al., 2001).

Many studies measured the spectral signature of coral reef benthos and substrates, either in the laboratory on a small scale or in-situ (Holden and Ledrew, 1999; Andréfouët and Payri, 2001; Hochberg and Atkinson, 2000, 2003; Kutser et al., 2003; Louchard et al., 2003; Joyce and Phinn, 2003; Purkis and Pasterkamp, 2004; Leiper et al., 2009) Others detected and discriminated between live corals, dead corals, bleached corals, algae, sponges, seagrasses and different substrates in different location worldwide. With the use of high spectral resolution measurements and the in-situ measurements, the discrimination between the wide-ranging classes of coral, algae, and sand become possible and more accurate (Hedley and Mumby, 2002).

The aim of this work is to integrate remote sensing technique with field data to assess and detect the surface and subsurface conditions along the study area and their effects on the marine habitats. Besides, building an institutional capability for accurate identification, classification, documentation, monitoring and assessment of coastal area activity.

\section{MATERIALS AND METHODS}

\section{Study area}

Hurghada was originally a small fishing village located at $33^{\circ} 41^{\prime} 03^{\prime \prime}$ to $34^{\circ} 04^{\prime}$ $03^{\prime \prime} \mathrm{E}$ and $27^{\circ} 00^{\prime} 14^{\prime \prime}$ to $27^{\circ} 25^{\prime} 30^{\prime \prime} \mathrm{N}$ (Fig., 1). The coastal plain of Hurghada extends for about $62 \mathrm{~km}$ length, from El Gouna to Sahel Hasheesh, and for about $35 \mathrm{~km}$ width with a total area of about $1625 \mathrm{~km} 2$, of which are $791 \mathrm{~km} 2$ inland and $834 \mathrm{~km} 2$ sea water. Later in the 1980s, it became the most famous tourist resort target on the Egyptian Red Sea. The growth of the coastal urban areas at Hurghada generates a range of threats to the nearby shoreline habitats. The construction of such touristic resorts essentially required infrastructure works on harbors, airports and mining the reef areas for construction materials (Bryant $\boldsymbol{e t}$ al., 1998). The National Institute of Oceanography and Fisheries (NIOF) coast was selected as a case study to test the extent of remote sensing mapping matches with the field data and its compatibility with the new technique of spectral signature for benthic cover. 29 sites in front of NIOF coast were chosen for achieve this aim. 


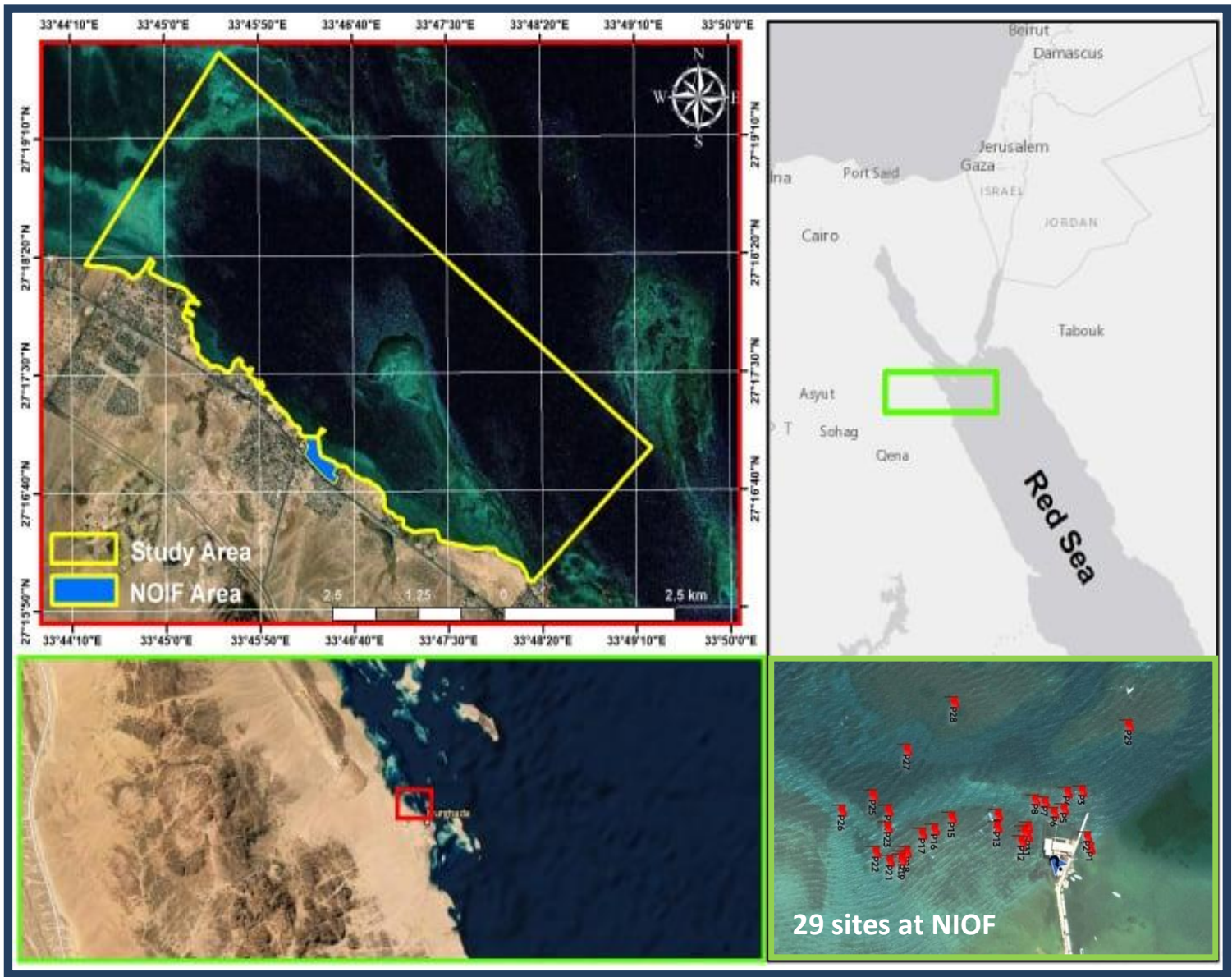

Figure 1. Sattalite image showing the study area and 29 sites in front of NIOF coast

\section{Field Work}

The field trip was done during December 2018 to cover the study area, collecting data about marine habitats. Check the results of satellite images analyses and, Collection of field observations and samples for measuring of surface and subsurface conditions were carried out to support remotely sensed data. Field selecting sites to measure spectral signatures for different marine habitats was done by using an instrument of SVC Spectroradiometer (Fig. 2).

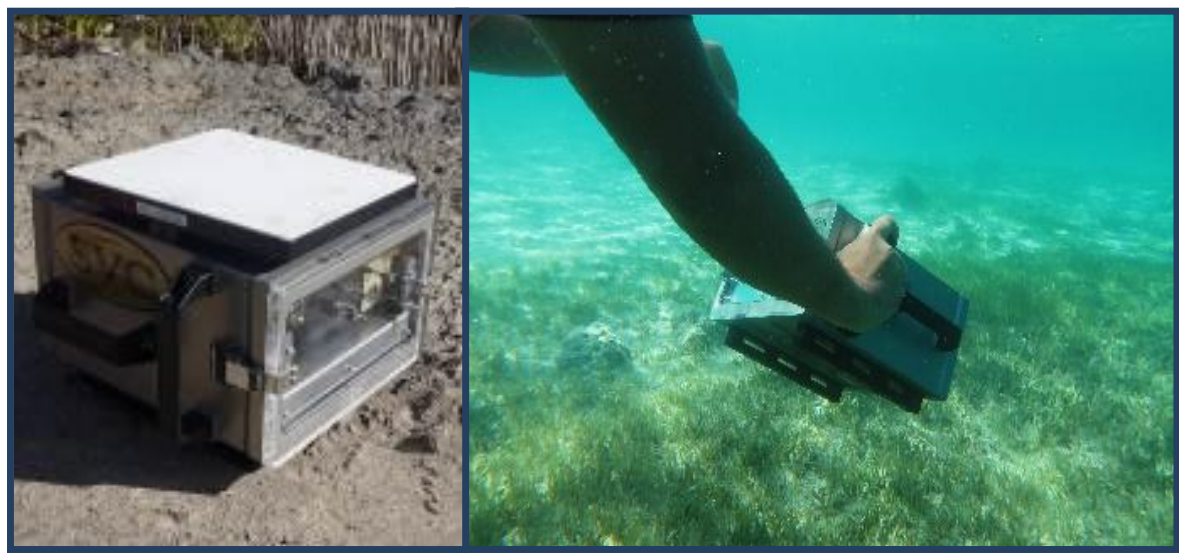

Figure 2. Spectroradiometer instrument, Field work. 


\section{Satellite images processing}

\subsection{Atmospheric correction:1}

\section{a. Conversion of Digital Number (DN) of the Landsat-8 OLI to Top Of Atmosphere (TOA) Reflectance:}

OLI band data (bands 1 through 7) of the collected scenes had been converted to the top of atmosphere planetary reflectance using rescaling coefficients provided in the image's metadata file. According to USGS the equation used to convert digital number values to TOA reflectance for OLI data is:

$$
\rho_{\lambda^{\prime}}=\mathrm{M}_{\rho} * \mathrm{Q}_{\mathrm{cal}}+\mathrm{A}_{\rho}
$$

\section{Where;}

- $\quad \rho_{\lambda^{\prime}}=$ TOA planetary reflectance, without correction for solar angle.

- $\mathrm{M}_{\rho}=$ Band-specific multiplicative rescaling factor from the metadata (Reflectance_MULT_band_x, where $\mathrm{x}$ is the band number).

- $\mathrm{A}_{\rho}=$ Band-specific additive rescaling factor from the metadata (Reflectance_ADD_band_x, where $\mathrm{x}$ is the band number).

- $\mathrm{Q}_{\mathrm{cal}}=$ Quantized and calibrated standard product pixel values (DN).

TOA reflectance with a correction for the sun angle is then:

$$
\rho_{\lambda}=\rho_{\lambda^{\prime}} / \sin \left(\theta_{S E}\right)
$$

\section{Where;}

- $\rho_{\lambda}=$ TOA planetary reflectance

- $\theta_{S E}=$ Local sun elevation angle. The scene center sun elevation angle in degrees is provided in the metadata file (SUN_ELEVATION). The value is converted to radians.

\section{b. TIRS Top of Atmosphere Brightness Temperature:}

Brightness temperature $\left(T_{B}\right)$ is a measurement of the radiance of the microwave radiation traveling upward from the top of the earth's atmosphere to the satellite. It is calculated through two steps as follows:

First step: TIRS band values (bands 10 and 11) are converted to spectral radiance using the radiance rescaling factors provided in the metadata file according to USGS as follows:

$$
\mathrm{L}_{\lambda}=\mathrm{M}_{\mathrm{L}} * \mathrm{Q}_{\mathrm{cal}}+\mathrm{A}_{\mathrm{L}}
$$

\section{Where;}

- $\mathrm{L}_{\lambda}=$ Spectral radiance (watts per square meter per steradian per micrometer $=\mathrm{W} /\left(\mathrm{m}^{2}\right.$ $* \mathrm{sr} * \mu \mathrm{m}))$.

- $\mathrm{M}_{\mathrm{L}}=$ Radiance multiplicative rescaling factor for the band (Radiance_MULT_band_x from the metadata, where $\mathrm{x}$ is the band number). 
- $\mathrm{A}_{\mathrm{L}}=$ Radiance additive rescaling factor for the band (Radiance_ADD_band_x from the metadata, where $\mathrm{x}$ is the band number).

- $\mathrm{Q}_{\mathrm{cal}}=$ Level 1 pixel value in $\mathrm{DN}$

Second step: spectral radiance values are then converted to at satellite brightness temperature for bands (10 and 11), which is the effective temperature viewed by the satellite under an assumption of unity emissivity. According to USGS the conversion formula is:

$$
\mathrm{T}_{\mathrm{B}}=\left[\mathrm{K} 2 / \operatorname{Ln}\left(\left(\mathrm{K} 1 / \mathrm{L}_{\lambda}\right)+1\right)\right]-272.15
$$

\section{Where;}

- $\mathrm{T}_{\mathrm{B}}=$ Top of Atmosphere Brightness Temperature, in degree Celsius.

- $\mathrm{L}_{\lambda}=$ Spectral radiance $\left(\mathrm{W} /\left(\mathrm{m}^{2} * \mathrm{sr} * \mu \mathrm{m}\right)\right)$

- $\mathrm{K} 1$ and $\mathrm{K} 2$ = Thermal conversion constant for the band from the metadata file.

The mean of the raster values of brightness temperature for bands (10 and 11) is calculated using cell statistics tool in ArcMap.

\subsection{Shorline extraction:}

Numerous semi-automatic and automatic methods are currently used to extract shoreline from optical satellite imagery. In the case of Landsat data, supervised and unsupervised classifications (Ekercin, 2007; Hereher et al., 2011), thresholding (Yamano et al., 2006; Cui and Li, 2011), and band rationing (Kuleli, 2010; Cui and Li, 2011) are among the most famous and simplest techniques.

The current study used the band rationing technique to extract shoreline features from the Landsat imagery. Band rationing exploits infrared wavebands that are highly absorbed by water (even turbid water) and strongly reflected by vegetation and soil (Cui and Li, 2011).

The study used the Digital Shoreline Analysis System (DSAS) tool, computer software that computes the rate-of-change statistics from multiple historic shoreline positions residing in a GIS, to detect shoreline changes from Landsat satellite data.

\subsection{Classification methods}

Commonly, the land cover classes are mapped from digital remotely sensed data through the process of a supervised digital image categorization (Campbell, 1987; Thomas et al., 1987). The main objective of the image categorization approach is to automatically classify all pixels in the image into land cover classes (Lillesand and Kiefer, 1994). Ordinarily, multispectral data are used to carry out the categorization and, actually, the spectral pattern in the data of each pixel is using as a numerical basis for classification. This means that the various feature kinds apparent different sets of digital numbers DNs depending on their ingrained spectral reflectance properties. 


\subsection{Maximum Likelihood Classifier}

The extreme likelihood classifier is one of the most popular methods of categorization in remote sensing technique, where the pixel with the maximum likelihood is classified into the corresponding class. The likelihood is defined as the posterior probability of a pixel belonging to class k.ENVI implements maximum likelihood classification by calculating the following discriminant functions for each pixel in the image (Richards, 1999):

$$
g_{i}(x)=\ln p\left(\omega_{i}\right)-1 / 2 \ln \left|\sum_{i}\right|-1 / 2\left(x-m_{i}\right)^{T} \sum_{i}^{-1}\left(x-m_{i}\right)
$$

\section{Where;}

- $\quad i=$ class

- $x=n$-dimensional data (where $n$ is the number of bands)

- $p\left(\omega_{i}\right)=$ probability that class $\omega_{i}$ occurs in the image and is assumed the same for all classes

- $\left|\Sigma_{i}\right|=$ determinant of the covariance matrix of the data in class $\omega_{i}$

- $\Sigma_{i}^{-1}=$ its inverse matrix

- $m_{i}=$ mean vector

The maximum likelihood method has an advantage from the view point of probability theory, but care must be taken with respect to the following items.

(1) Sufficient ground truth data should be sampled to allow estimation of the mean vector and the variance-covariance matrix of population.

(2) The inverse matrix of the variance-covariance matrix becomes unstable in the case where there exists very high correlation between two bands or the ground truth data are very homogeneous. In such cases, the number of bands should be reduced by a principal component analysis.

(3) When the distribution of the population does not follow the normal distribution, the maximum likelihood method cannot be applied.

\section{RESULTS AND DISCUSSION}

\section{Description of reef zonation along Hurghada Coast:}

The Beach zone: Shoreward, the area is edged by a raised reefal limestone formation about $1 \mathrm{~m}$ in height, which was deposited during late Pleistocene or early Holocene (El-Sayed, 1984). A narrow sandy strip delineates the shore of the area. The beach is mostly composed of a poorly sorted mixture of gravel, sand, mostly as coral fragments and shell remains admixed mud (El-Sayed, 1984). The Back-reef zone: The lagoon and back-reef zone have a rocky substratum covered with thin layer of unconsolidated sediments. The maximum water depth is about $6 \mathrm{~m}$ and the width of this zone is about $400 \mathrm{~m}$. Reef Flat and Fore Reef zone: The reef formation extends for about $250 \mathrm{~m}$, being interrupted by patches of sand. The reef is characterized by dense coverage 
of colonies of Acropora, Tubipora, Millepora, Stylophora and giant Platygyra sp. The reef drops off to a sandy ledge at about $7 \mathrm{~m}$. Off-shore zone: This area lies off-shore where the depth exceeds $25 \mathrm{~m}$. It is characterized by a dominance of mud.

Profiles sectors were selected through Hurghada city cut land to sea. The first profile at north of the city show variable change between heights of about $200 \mathrm{~m}$ near to the coastline and deep into the sea till depth of $50 \mathrm{~m}$ because this sector cross through the northern islands. The next profile through mid of the city, show gentle slope on the land, but into the sea it is slopped from the shore to the bottom of depth about 400m in distance of about 1 kilometer. The last profile south of the city, it is gently dropped from height of $200 \mathrm{~m}$ and into the sea decreased until reach depth of about 900m (Fig. 3).

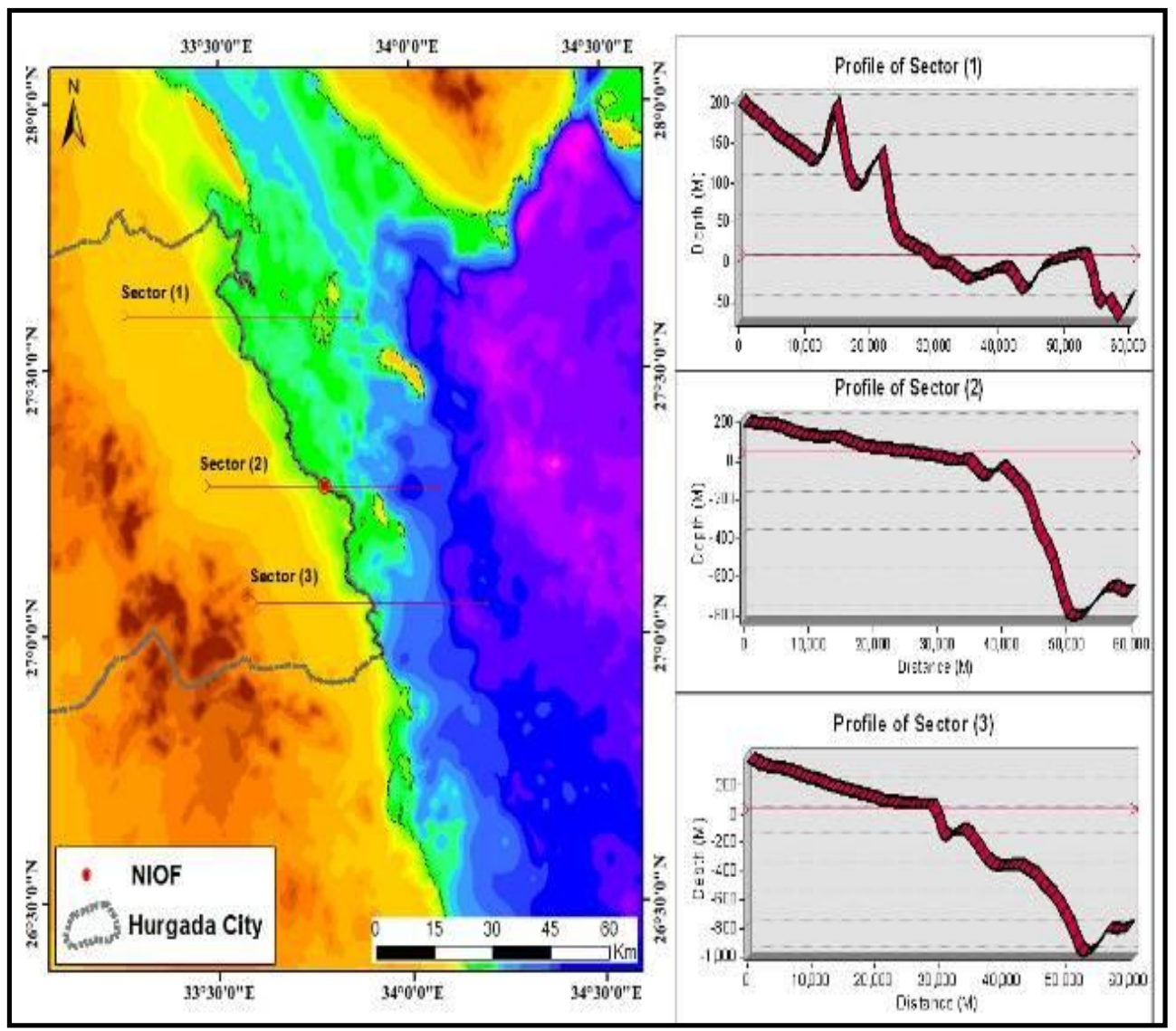

Figure 3. Profile sectors show heights and bathymetry along coastline of Hurghada city.

\section{Shore line changes:}

It is fully obvious that the shoreline in the study area is stable and no areas of any natural accretions/erosions detected along Hurghada coast. This in fact attributed to the rocky nature of the coast with abundance of coralline terraces in addition to absence of true strong waves and drifting currents. However, processes of landfilling and dredging (Fig., 4) in order to widen and extend the beaches to accommodate touristic increasing have observed. Such processes influences on natural shoretline and the biological diversity which inhabiting the coastal area and came on the expense of the coral reef 
communities. The observed dredging of hard rocks and corals related to construction of swimming bays which appear have erosion patterns, and landfilling for constructions of marinas which seem as accretion patterns. The observed satellite image of 1984 (Figure 4) shows the coast of Hurghada, before the development activities with no evidence of anthropogenic interference, while in 2020 image the situation is completely changed, patterns of dredging and landfilling detected at different locations of the coast.

Erosion/accretion pattern on shoreline of Hurghada from years 1973 to 2018 recorded and illustrated (Fig., 4). The increase in both landfilling and dredging seems contemporaneous to the rise in the tourism activities with consequent construction of the tourist resorts facilities and infrastructure. Most constructions have been already fixed their infrastructure, in addition to decline in number of tourists because of the political situation However, still areas of erosion detected north of Hurghada related to marine and coastal works in El-Guna resort.

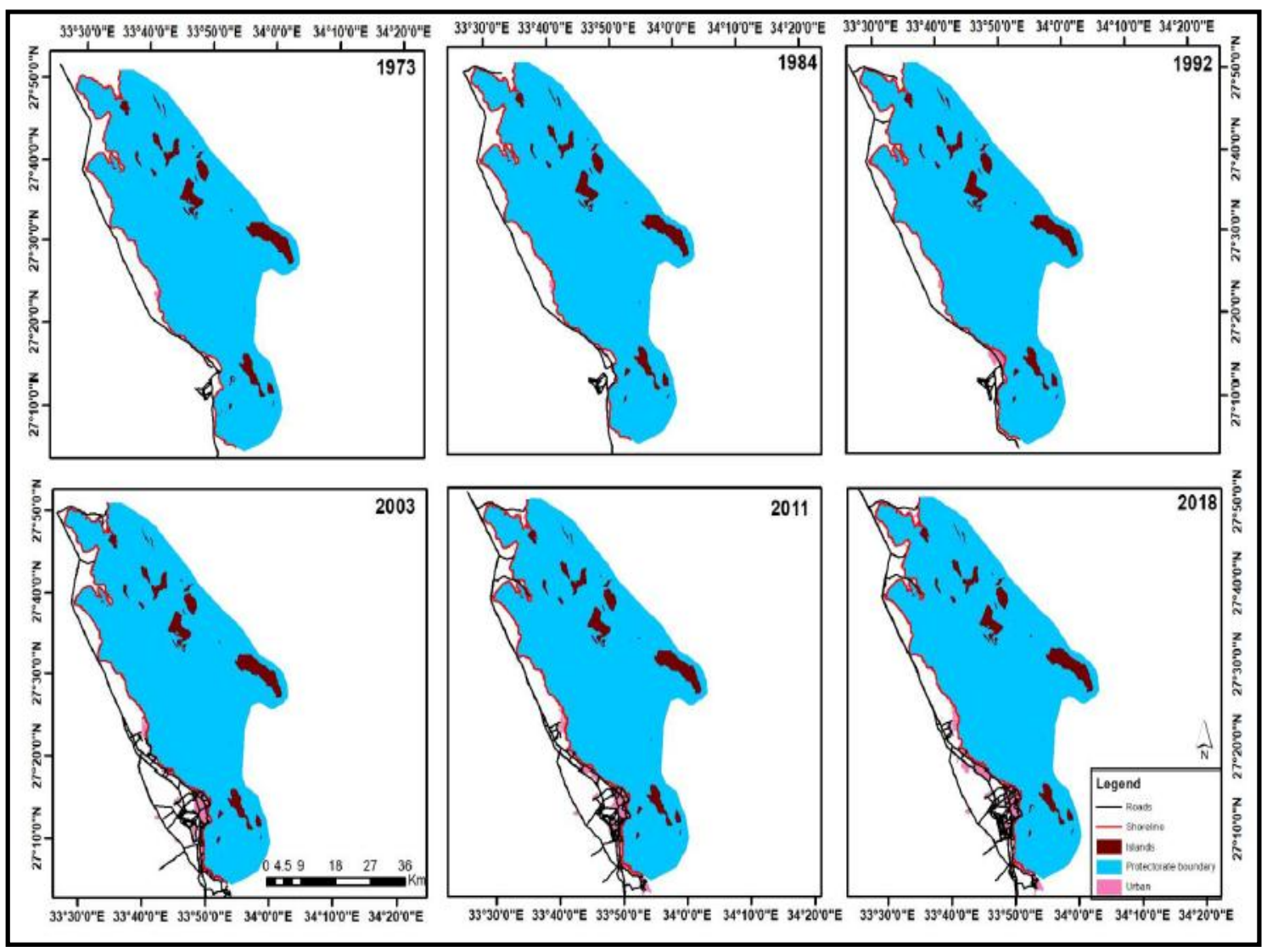

Figure 4. Hurghada shoreline change detection from 1973 to 2018.

\section{NIOF coastal area as a case study for spectral signature profile.}

\subsection{Water Quality along the study area}

the Run-off produced from land-based anthropogenic activities which containing raised concentrations of sediment, pollutants, nutrients, wastes and pesticides has a considerable influence on water quality and the ecologic status of nearshore areas of the 
Hurghada city. The actual and potential effects of the concentrations of the increased pollutant range from bioaccumulation of pollutants and contaminants and decreased photosynthetic ability to main change in the community structure and the ecosystems health. Remote sensing help in monitoring and mapping water quality like (Ammonia, Nitrite, $\mathrm{pH}$, Phosphate, Temperature) as in Figures (5 a:e).

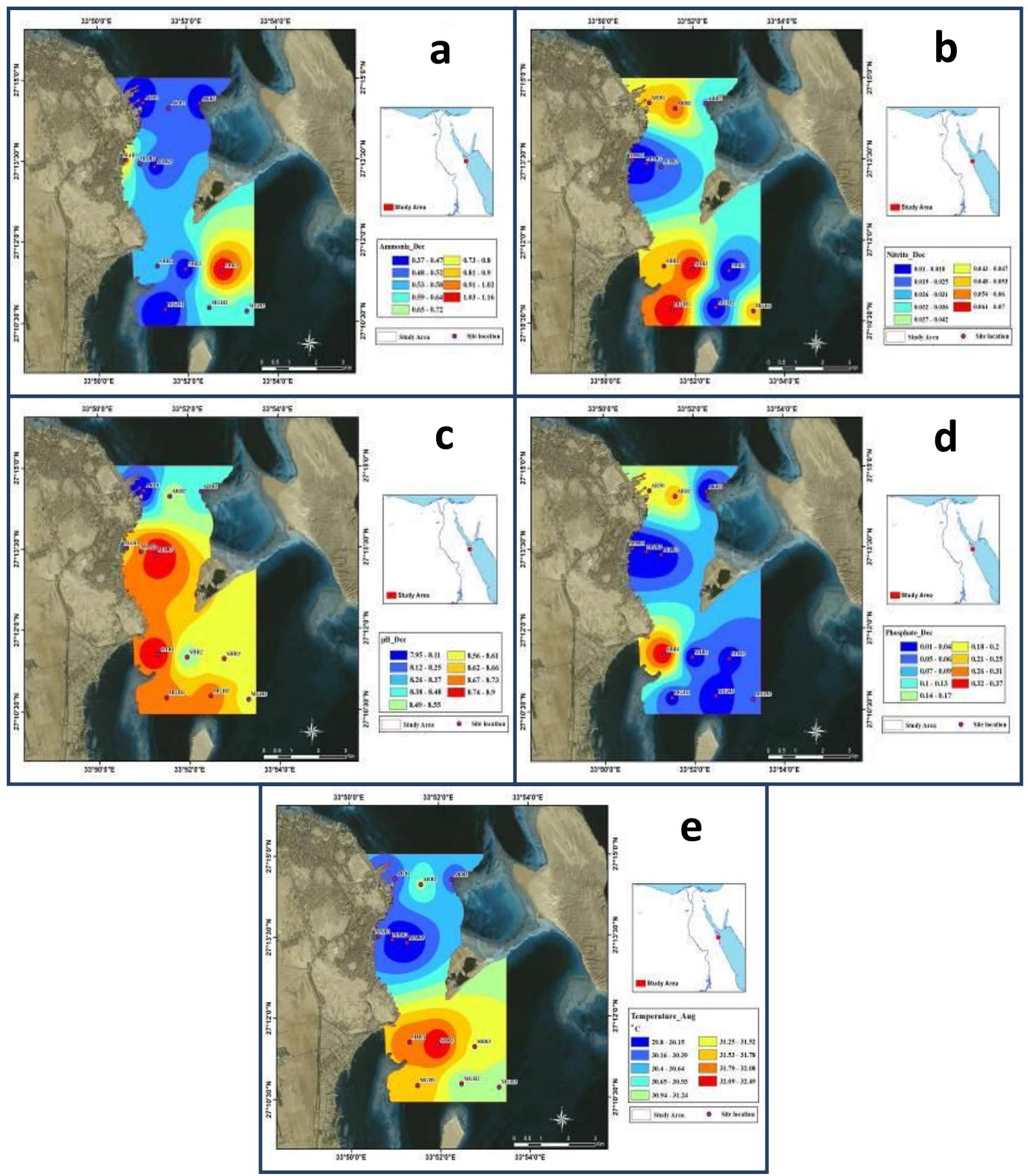

Figure 5. Water quality along study area; a) Ammonia, b) Nitrite, c) pH, d) Phosphate and e) Temperature. 
The physico-chemical characteristics of the Red Sea depend on the dynamics of its water as well as on the geographical location. Beltagi (1984) suggested that, in the Red Sea, due to the exceptionally high water temperature, all the biochemical processes proceed all year round at high rates. However, the Red Sea does not receive any significant nutrient supply from river out flow. Therefore, the replenishment of these elements in the Red Sea depends upon the inflow of Indian Ocean water through Bab El Mandab, $\left(12.510^{3} \mathrm{k}^{3} \mathrm{y}^{1}\right)$ and the mixing of surface with deeper waters. These results are consistent with the oligotrophic characteristics of the Red Sea coastal waters.

\subsection{Habitat mapping of NIOF Coastal area}

The coastal area of NIOF contains a high diversity of the most of marine habitats represented in the Red Sea. The main habitat in this area is coral reef mainly from the type of fringing coral reefs in addition Patch reef. These reefs are living over the coralline limestone the end of a narrow tidal flat. The fringing reefs extends parallel to the coast and ended at the origin of a submerged marine strip (firth) at the south coast of the study area this submerged marine strip composed from reef flat and surrounded by fringing reef and act as Breaker for waves. The reef formation extends for about $250 \mathrm{~m}$ composed from wide reef flat zone being interrupted by patches of sand and Seagrass meadows. The reef in the study area is characterized by dense coverage of colonies of Acropora, Tubipora, Millepora, Stylophora and giant Platygyra sp. The main second habitat in the study area is seagrass meadows which spread in scattered patches of many species along the study area. The seagrass meadows are considered conspicuous and important ecologically. The sediments of reef and sea marginal lagoon are the most distinctive sedimentary deposits near the shore areas of the Red Sea. The main second habitat in the study area is seagrass meadows which spread in scattered patches of many seagrass species along the study area. The seagrass meadows are considered conspicuous and important ecologically in the area. There are many relatively distinctive set of microhabitats in both the intertidal and subtidal zone such as an enormous area of sandy bottom, bits of mixed sandy-muddy bottom, some of that mixed with macroalgae and other with seagrass. After the submerged marine strip, the deep water is arising in the offshore zone where the depth exceeds $25 \mathrm{~m}$. It is characterized by a dominance of mud and sand bottom then El-Fanadir island is appear that descend into the continental shelf at deep sea (Fig. 6). 


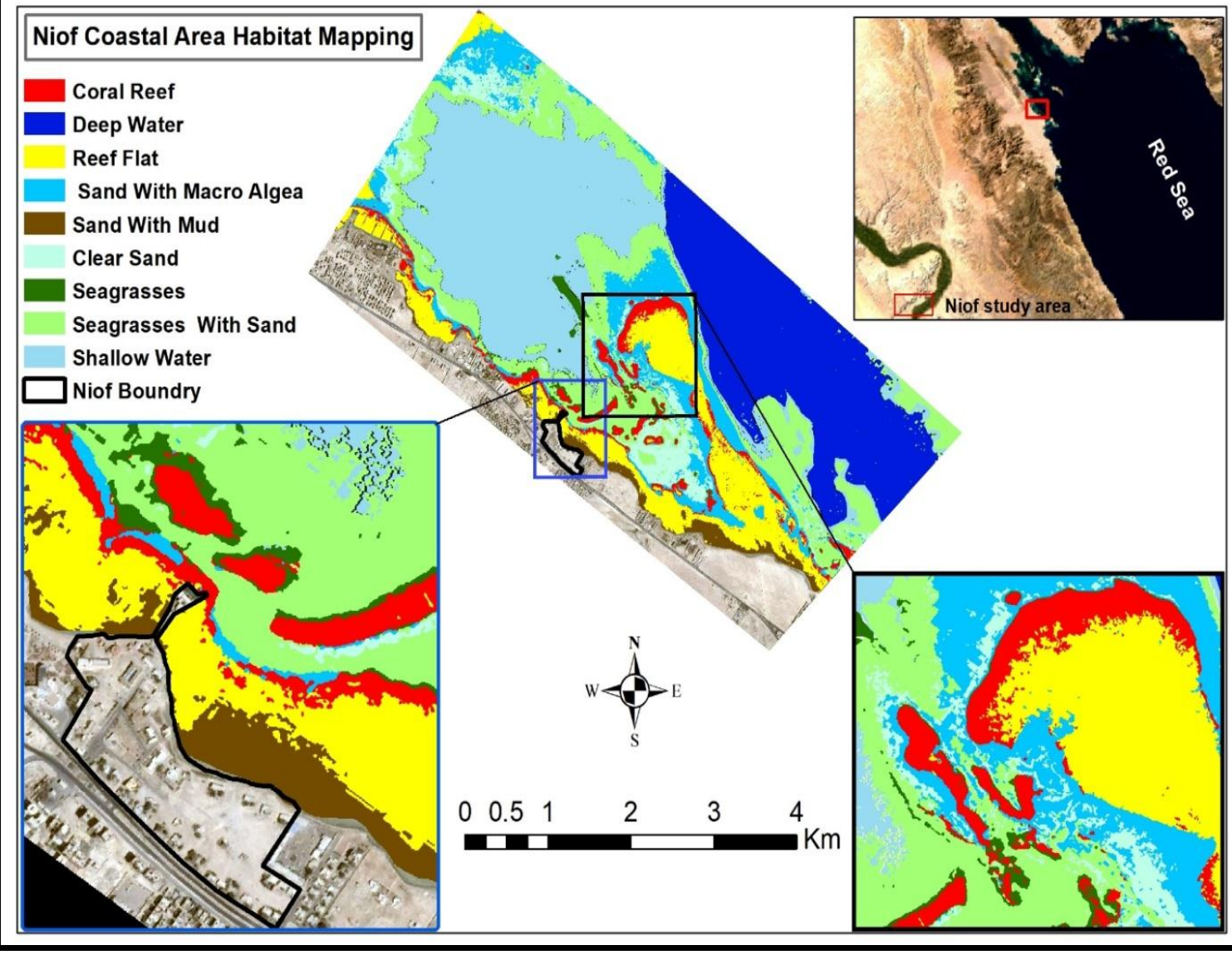

Figure 6. Habitat mapping of NIOF Coastal area

\subsection{Spectral signature profiles}

According to the present study, spectral signature profiles investigations in the study area greatly corresponds to the field survey and habitat mapping by GIS technique (Figs.7, 8, 9, 10). Where, Figure (7) clarifies that there are four spectral signatures for bottom type in the study site, while the field survey confirmed that. Accordingly, the main bottom types in the study area was varied between sandy, muddy, mixed sandymuddy, mixed sandy-rocky and reef flat substrate, the most common one in the study area is the sandy bottom.

In this context, a four seagrasses species were identified in the study area during field survey. Astoundingly, Spectroradiometer instrument recognize four different spectral signatures have different reflectance at different wavelength related to seagrasses species. These species namely; Halodule uninervis, Thalassodendron ciliatum, Halophila stipulacea and Thalassia hemprichii (Fig. 8).

On the other hand, there were four sea weeds species recorded during this study, this species namely; Caulerpa racemosa, Sargassum cenereum, Sargassum vulgareand Cystoseira myrica. The spectral reflectance measurements in the surveyed sites 
confirmed the presence of these species that have different reflectance at different wavelength (Fig. 9).

Dumbfoundingly, the corals in the field survey during this study were represented by sixteen species of coral reef namely; Acropora humilis, Porites nodifera, Fungi horida, Porites columnaris, Gonipora ciliates, Acropora euristoma, Acropora gemifera, Geniopora columna, Favia favus, Platygyra sinensis, Favites paraflexus, Galaxea fascicularis, Sarcophyton sp., Favia rotumana, Oxypora sp., and Stylophora pistillata. Accordingly, the spectral reflectance measurements confirmed the presence of many species, but the main common species were mentioned in Figure (10). The spectral reflectance measurements in the survey sites showed that all recorded species have different reflectance at different wavelength.

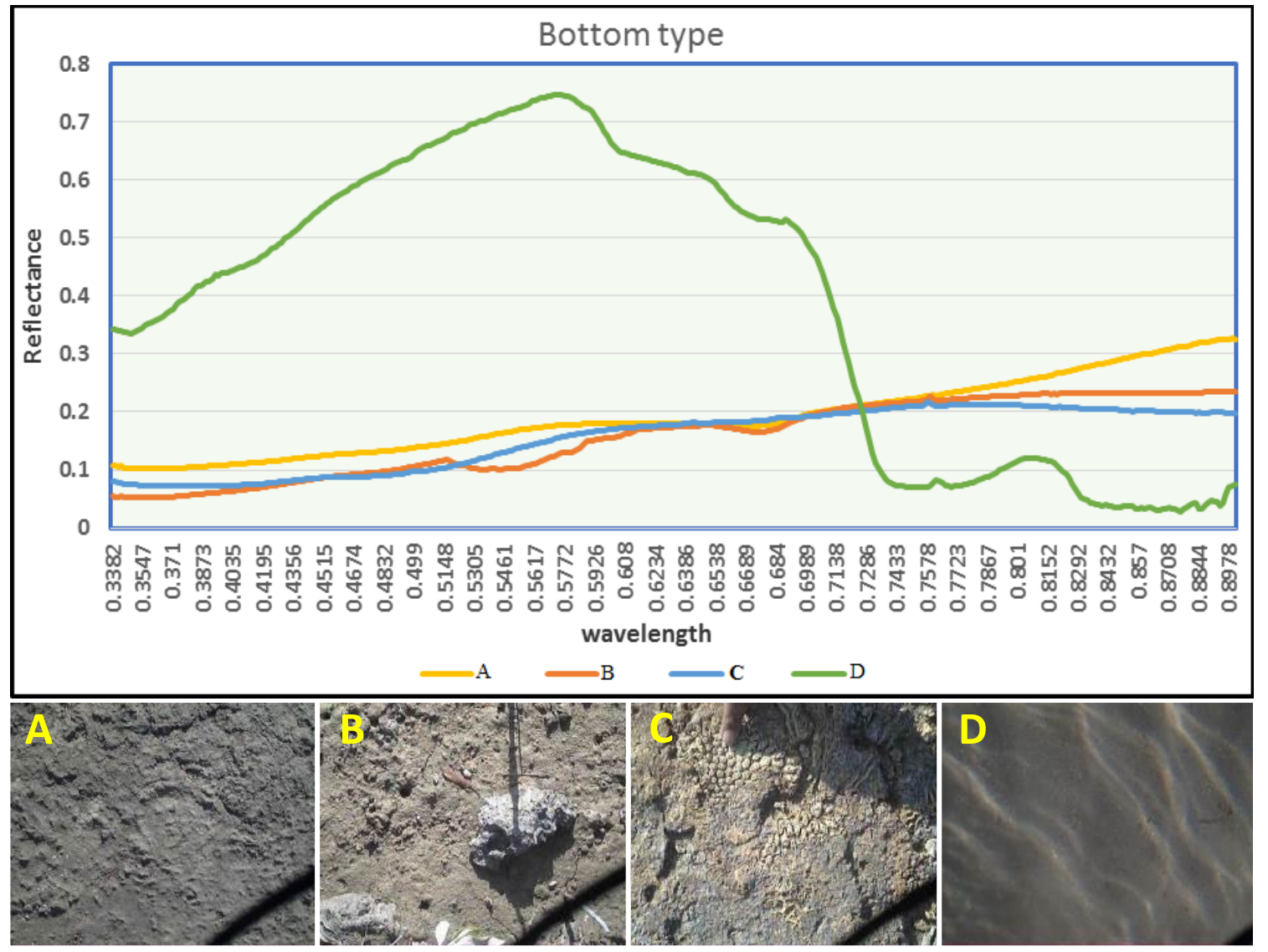

Figure 7. Spectral signature profiles and field survey of bottom types along NIOF site showing four types of bottom; A) mixed sandy- muddy, B) mixed sandy-rocky, C) Reef flat and D) Sandy bottoms. 


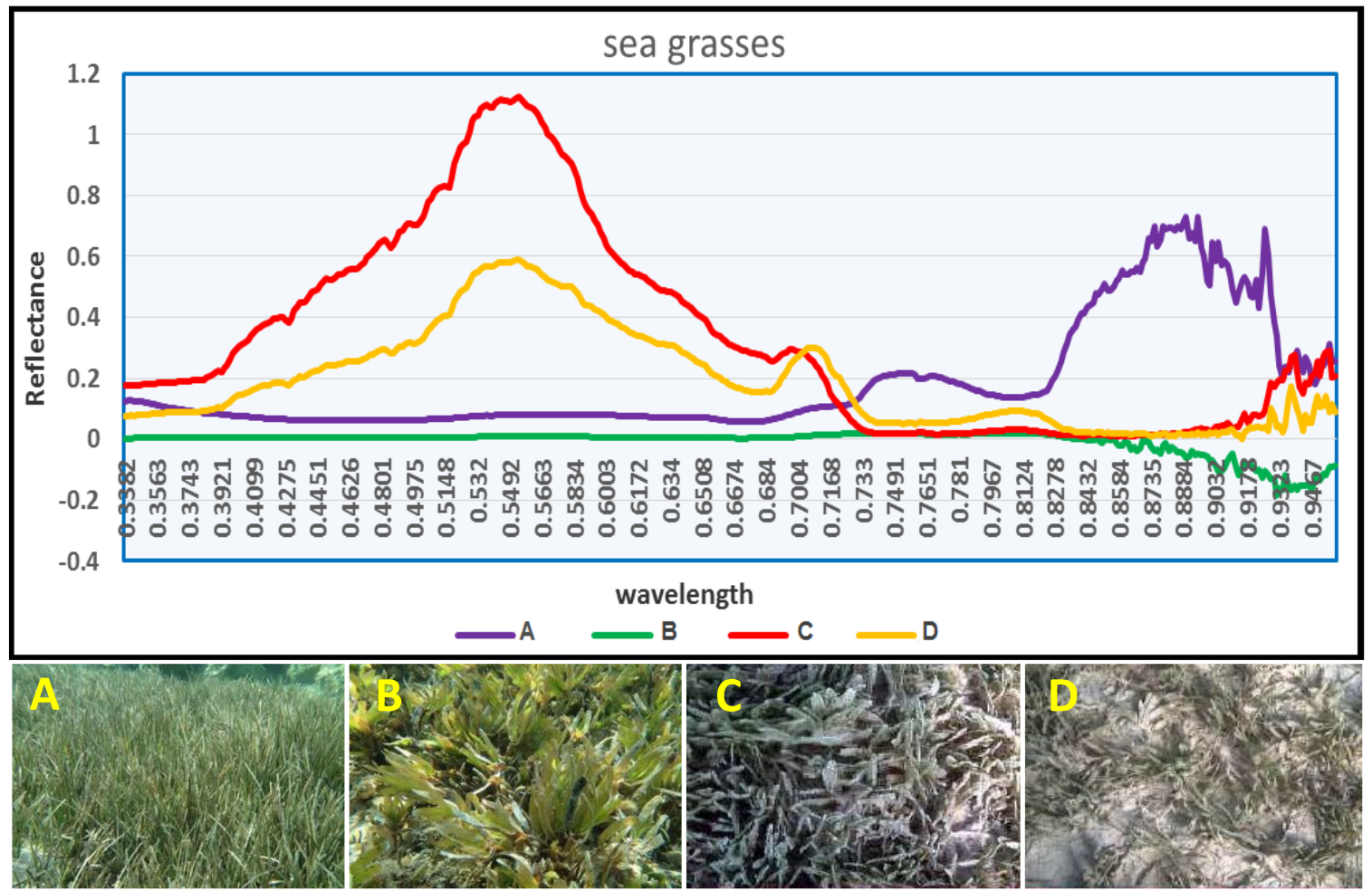

Figure 8. Spectral signature profiles and field survey of bottom types along NIOF site showing four Seagrasses species; A) Halodule uninervis, B) Thalassodendron ciliatum, C) Halophila stipulacea and D) Thalassia hemprichii.

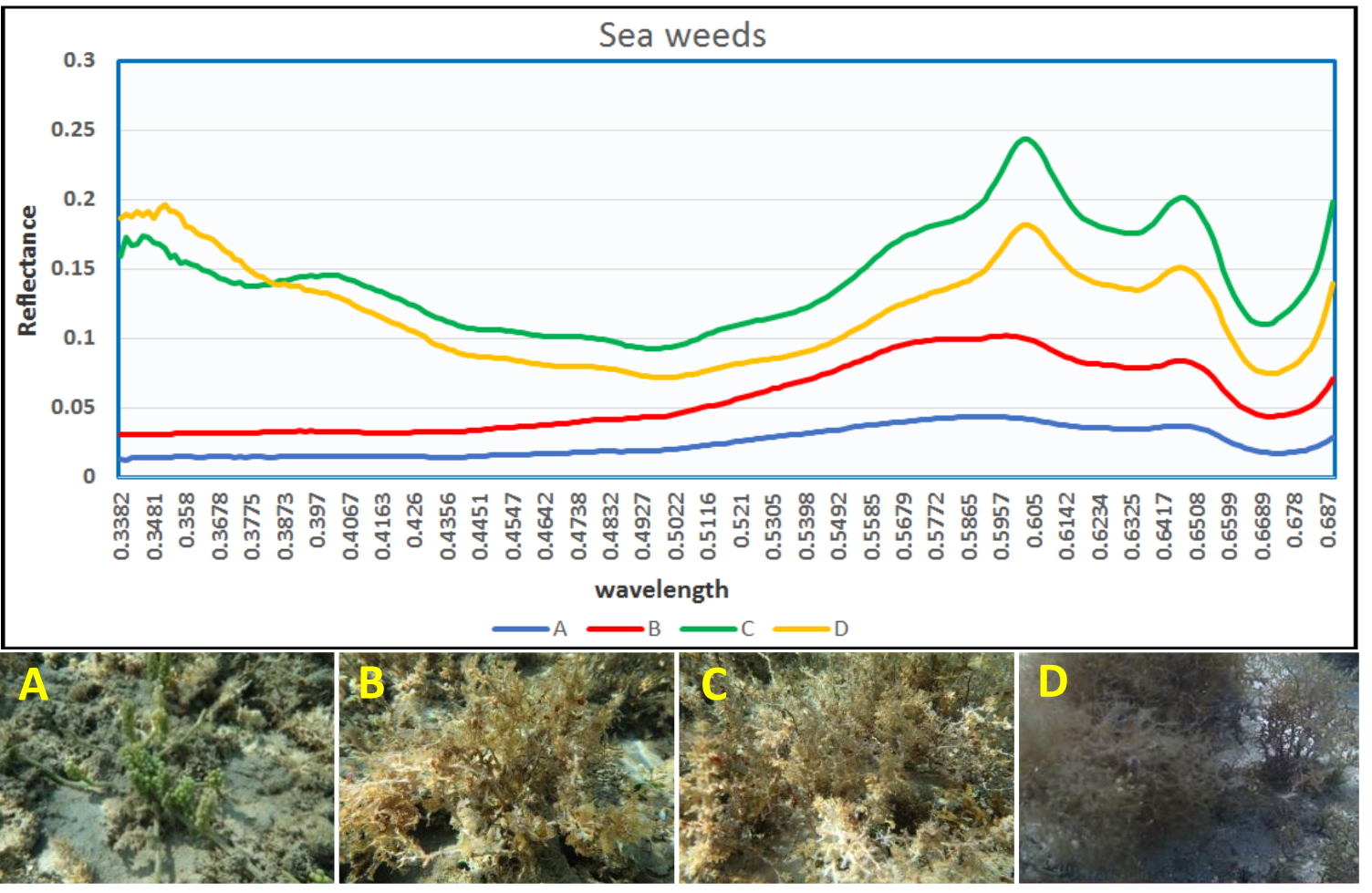

Figure 9. Spectral signature profiles and field survey of bottom types along NIOF site showing four Sea weeds species; A) Caulerpara cemosa, B) Sargassum cenereum, C) Sargassum vulgare and D) Cystoseira myrica. 


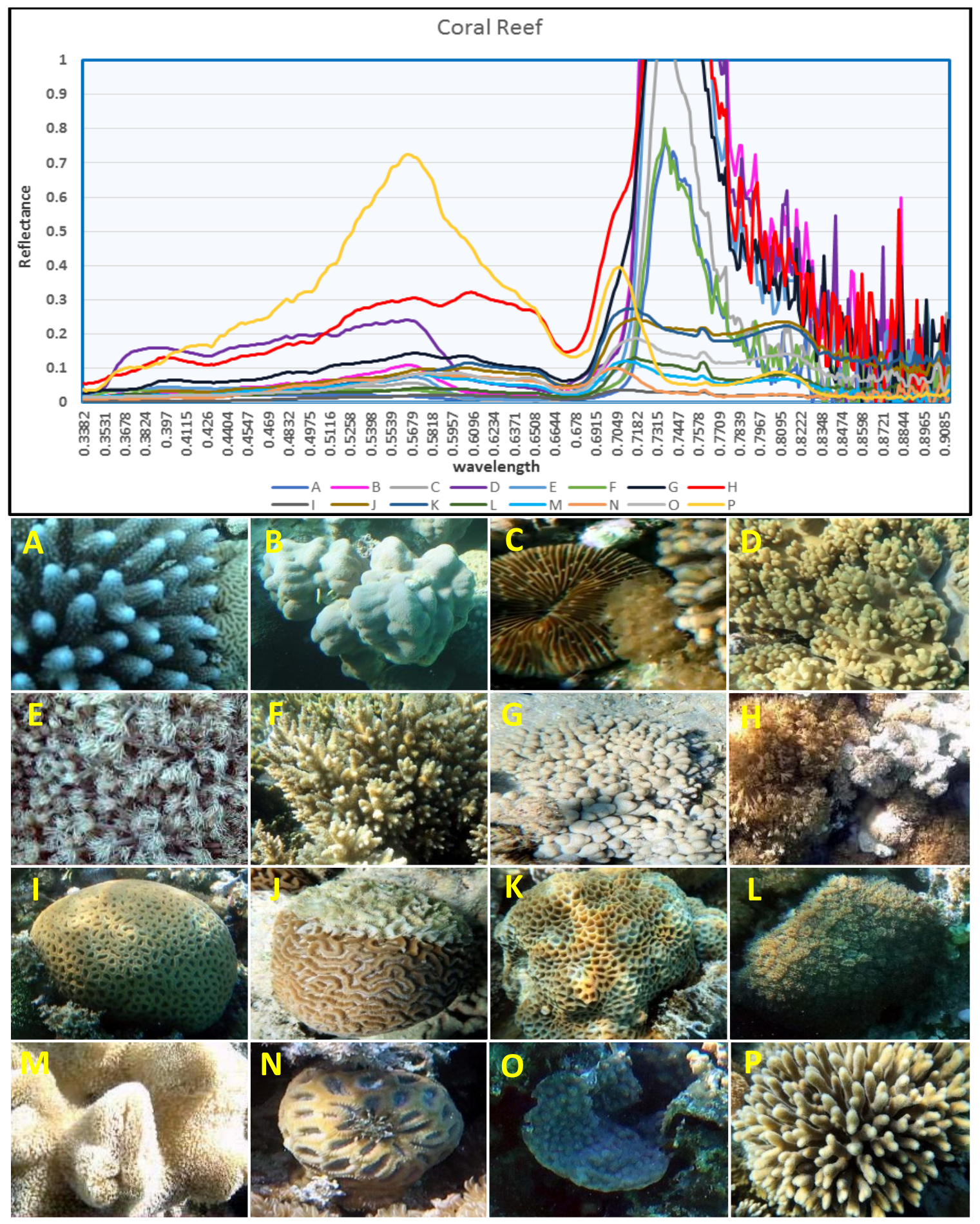

Figure 10. Spectral signature profiles and field survey of bottom types along NIOF site showing sixteen corals species; A) Acropora humilis, B) Porites nodifera, C) Fungi horida, D) Porites columnaris, E) Gonipora ciliates, F) Acropora euristoma, G) Acropora gemifera, H) Geniopora columna, I) Favia favus, J) Platygyra sinensis, K) Favites paraflexus, L) Galaxea fascicularis, M) Sarcophyton sp., N) Favia rotumana, O) Oxypora sp., and P) Stylophora pistillata. 
At the northern Red Sea near Gubal Island, Minghelli-Roman et al., (2002) examined the in-situ underwater spectral reflectance characteristics of 14 genera collected from different coral colonies at depths of 1-20 m. While at the southern of the Red Sea in Marsa Shagra, Purkis and Pasterkamp (2004) used the in-situ spectral reflectance measurements (above the water surface) to evaluate a supervised classification of Landsat images. In past studies, high spectral resolution spectrometer data acquired in-situ was employed, with little or no intervening water column Joyce and Phinn (2003). Hochberg and Atkinson (2003), reported that 12 coral reef benthos and substrate types (fleshy brown, green, and red algae; non-fleshy encrusting calcareous and turf algae; bleached, blue, and brown live coral; soft/gorgonian coral; seagrass; terrigenous mud; and carbonate sand) may possibly be recognized from in-situ measured spectral reflectance data, the study reported that measurements to be consistent globally.

Joyce et al. (2013) created a spectral index for mapping the cover of live coral using CASI-2 airborne hyperspectral high spatial resolution imagery of Heron Reef, Australia. They stated that the index of live coral cover is simple and viable pattern to evaluate the amount of live coral reef in clear-water. Better accuracies may be obtained through the data included from airborne sensors like the Compact Airborne Spectrographic Imager (Mumby et al., 1998; Bertels et al., 2008) or in combination with other satellite data (Rowlands et al., 2008).

The present study recommended continuing on establishment of spectral library for the bottom benthos and different marine habitats of the Red Sea. Dekker et al. (2010) and Rasaiah et al. (2015) recommended a necessity to establish a set of standards for the capture, storage and use of spectral reflectance libraries which measured in situ to assess the coral reef environment from airborne or satellite imagery. Universal valuable of field spectral data required complete metadata (what is measured, how, by what instrument, where and by whom and under what conditions). Standardized spectral measurement methods where spectra from habitats in different regions may be usefully compared.

\section{REFERENCES}

Andréfouët, S. and C. Payri. (2001). Scaling-up carbon and carbonate metabolism of coral reefs using in-situ data and remote sensing. Coral Reefs, 19: 259-269.

Australia, G. (2012). "OzCoasts: Australian Online Coastal Information." (http://www.ozcoasts.org.au)

Beltagi, A. I. (1984). Oceanographic and Fisheries Investigations in the Egyptian Red Sea. Special publication, Academy of Scientific Research and Technology, NIOF Egypt.

Bertels, L.; Vanderstraete, T.; Van Coillie, S.; Knaeps, E.; Sterckx, S.; Goossens, R. and Deronde, B. (2008). Mapping of coral reefs using hyperspectral CASI data; a case study: Fordata, Tanimbar, Indonesia. Int. J. Remote Sens., 29: 2359-2391.

Blakey, T.; Melesse, A. and Hall, M. O. (2015). "Supervised Classification of Benthic Reflectance in Shallow Subtropical Waters Using a Generalized Pixel-based Classifier across a Time Series.” Remote Sensing, 7(5): 5098-116. 
Braithwaite, C. J. R. (1987). Geology and Palaeogeography of the Red Sea Region. In "The Red Sea." Edwards, A. J., and Head, S. M. (Eds.). Perg. Pre., pp. 22-44.

Brown, C. J.; Todd, B. J.; Vladimir, E. K. and Pickrill, R. A. (2011). "Image-based Classification of MultibeamSonar Backscatter Data for Objective Surficial Sediment Mapping of Georges Bank, Canada.” Continental Shelf Research, 31(2): S110-9.

Bryant, D.; Burke, L.; McManus, J. and Spalding, M. (1998). Reefs at Risk: A Mapbased Indicator of Threats to the World's Coral Reefs. World Resources Institute, International Center for Living Aquatic Resources Management, World Conservation Monitoring Centre, and United Nations Environment Programme, Washington D.C.

Call, K. A.; Hardy, J. T. and Wallin, D. O. (2003). "Coral Reef Habitat Discrimination Using Multivariate Spectral Analysis and Satellite Remote Sensing." Inte. J. of Remote Sens., 24(13): 2627-39.

Campbell, J. B. (1987). Introduction into remote sensing. The Guildford Press, New York.

Coggan, R. and Diesing, M. (2011). "The Seabed Habitatsof the Central English Channel: A Generation on from Holme and Cabioch, How Do Their Interpretations Match-up to Modern Mapping Techniques?" Continental Shelf Research, 31(2): S13250 .

Cui, B. and Li, X. (2011). Coastline change of Yellow River estuary and its response to the sediment and runoff (1976-2005). Geomorphology 127: 32-40

Dekker, A. G.; Brando, V. E.; Anstee, J. M.; Botha, A. J.; Park, Y. J.; Daniel, P.; Malthus, T. J. M.; Phinn, S. R.; Roelfsema, C. M.; Leiper, I. A. and Fyfe, S. (2010). A Comparison of Spectral Measurement Methods for Substratum and Benthic Features in Seagrass and Coral Reef Environments. In Proceedings of the ASD and IEEE GRS; Art, Science and Applications of Reflectance Spectroscopy Symposium, Boulder, CO, USA, Vol. II, pp. 15.

Ekercin, S. (2007). Multitemporal change detection on the Salt Lake and it vicinity by integrating remote sensing and geographic information system. Ph.D. Thesis, Istanbul Technical University, Institute of Science and Technology, Istanbul.

El-Damhougy, K. A.; Bashar, M. A. E; El-Naggar, H. A.; Ibrahim, H. A. and AbouSenna, F.M. (2017a). GC-MS analysis of bioactive components of Callyspongia crassa (Porifera) from Gulf of Aqaba, Red Sea (Egypt). Al-Azhar Bulletin of Science, 9 Conf.: 111-118.

El-Damhougy, K. A.; El-Naggar, H. A.; Ibrahim, H. A.; Bashar, M. A. and AbouSenna, F. M. (2017b). Biological activities of some marine sponge extracts from Aqaba Gulf, Red Sea, Egypt. Int. J. Fish. Aquat. Stud., 5(2): 652-659.

El-Damhougy, K. A.; El-Naggar, H. A.; Aly-Eldeen, M.A. and Abdella, M.H. (2019). Zooplankton groups in Lake Timsah, Suez Canal, Egypt. Egypt. J. Aquat. Biol. Fish., 23(2): 303-316.

El-Naggar H. A. (2020). Human Impacts on Coral Reef Ecosystem. In: "Natural Resources Management and Biological Sciences" Edward R Rhodes (Eds.) IntechOpen, DOI: 10.5772/intechopen.88841. Available from: https://www. intechopen.com/online-first/human-impacts-on-coral-reef-ecosystem

El-Naggar, H. A.; El-Gayar, E. E.; Mohamed, E. N. E. and Mona M.H. (2017). Intertidal Macro-benthos diversity and their relation with tourism activities at Blue Hole Diving Site, Dahab, South Sinai, Egypt. SYLWAN, 161(11): 227- 251. 
El-Naggar, H. A.; Khalaf Allah, H. M. M.; Masood, M. F.; Shaban, W. M. and Bashar, M. A. E. (2019). Food and feeding habits of some Nile River fish and their relationship to the availability of natural food resources. Egypt. J. Aquat. Biol. Fish., 45(3): 273-280.

El-Sayed, M. Kh. (1984). Reefal sediments of Al-Ghardaqa, Northern Red Sea Egypt, Mar. Geol., 56: 259-271.

Farrag, M. M. S.; El-Naggar, H. A.; Abou-Mahmoud, M. M. A.; Alabssawy, A. N.; Ahmed, H. O.; Abo-Taleb, H. A. and Kostas, K. (2019). Marine biodiversity patterns off Alexandria area, southeastern Mediterranean Sea, Egypt. Environ. Monit. Assess., 191:367. https://doi.org/10.1007/s10661-019-7471-7.

Hamel, M. A. and Andrefouet, S. (2010). "Using very High Resolution Remote Sensing for the Management of Coral Reef Fisheries: Review and Perspectives." Mar. Pollut. Bull., 60 (9): 1397-405.

Head, S. M. (1987). Coral and Coral Reef of the Red Sea. In the 'Red Sea'. Edwards, A. J. and Head, S. M. (Eds.), Perg. Pre., 128-151.

Hedley, J. and Mumby, P. (2002). Biological and remote sensing perspectives of pigmentation in coral reef organisms. Advances in Marine Biology, 43: 279-317.

Hereher, M.; Salem, M. and Darwish, D. (2011). Mapping water quality of Burullus Lagoon using remote sensing and geographic information system. J. Am. Sci. 7(1): 138-143.

Hochberg, E. and Atkinson, M. (2000). Spectral discrimination of coral reef benthic communities. Coral Reefs, 19: 164-171.

Hochberg, E. and Atkinson, M. (2003). Capabilities of remote sensors to classify coral, algae, and sand as pure and mixed spectra. Remote Sens. Environ., 85: 174-189.

Holden, H. and LeDrew, E. (1999). Hyperspectral identification of coral reef features. Int. J. Remote Sens., 20: 2545-2563.

Ibrahim, H. A.; El-Naggar, H. A.; El-Damhougy, K. A.; Bashar, M. A. E. and AbouSenna, F. M. (2017). Callyspongia crassa and C. siphonella (Porifera, Callyspongiidae) as a potential source for medical bioactive substances-Aqaba Gulf, Red Sea, Egypt. The Journal of Basic and Applied Zoology, 78:7, 10 pp.

Joyce, K. E. and Phinn, S. R. (2003). Hyperspectral analysis of chlorophyll content and photosynthetic capacityof coral reef substrates. Limnology and Oceanography. 48: 489-496.

Joyce, L. A.; Briske, D. D.; Brown, J. R.; Polley, H. W.; McCarl, B. A. and Bailey, D. W. (2013). Climate change and North American rangelands: Assessment of mitigation and adaptation strategies. Rangeland Ecology and Management, 66(5): 512-528.

Kuleli, T. (2010). Quantitative analysis of shoreline changes at the mediterranean coast in Turkey. Environmental Monitoring and Assessment, 167(1-4): 387-397.

Kutser, T.; Dekker, A. and Skirving., W. (2003). Modelling spectral discrimination of Great Barrier Reef benthic communities by remote sensing instruments. Limnology Oceanography, 48(1, part 2): 497-510.

Leiper, I. A.; Siebeck, U. E.; Marshall, N. J. and Phinn, S. R. (2009). Coral health monitoring: linking coral colour and remote sensing techniques. Can. J. Remote Sens., 35: 276-286. 
Lillesand, T. M. and Kieffer, R. W. (1994) Remote sensing and image interpretation, $3^{\text {rd }}$ edn. Wiley, New York

Louchard, E. M.; Reid, R. P.; Stephens, F. C.; Davis, C. O.; Leathers, R. A. and Downes, T. V. (2003). Optical remote sensing of benthic habitats and bathymetry in coastal environments at Lee StockingIsland, Bahamas: a comparative spectral classification approach. Limnol. Oceanogr., 48: 511-521.

Lucas, M. Q. and Goodman, J. (2014). "Linking Coral Reef Remote Sensing and Field Ecology: It's a Matter of Scale." Journal of Marian Science and Engineering, 3(1): 120.

Lubin, D.; Li, W.; Dustan, P.; Mazel, C. H. and Stamnes, K. (2001). Spectral Signatures of Coral Reefs: Features from Space. Remote Sens. Environ., 75(1): 127137

Mansour, A. F.; El-Naggar, N. A.; El-Naggar, H. A.; Zakaria, H. Y., and AboSenna, F. M. (2020). Temporal and spatial variations of zooplankton distribution in the Eastern Harbor, Alexandria, Egypt. Egypt. J. Aquat. Biol. Fish., 24(4): 421-435.

Mansour, A. F.; El-Naggar, N. A.; El-Naggar, H. A.; Zakaria, H. Y. and Abo-Senna, F. M. (2020). Temporal and spatial variations of zooplankton distribution in the Eastern Harbor, Alexandria, Egypt. Egypt. Aquat. Biol. Fish., 24(4): 421-435.

Metwally A. S., El-Naggar H. A. El-Damhougy K. A., Bashar M. A. E., Ashour M. and Abo-Taleb H. A. H. (2020). GC-MS analysis of bioactive components in six different crude extracts from the Soft Coral (Sinularia maxim) collected from Ras Mohamed, Aqaba Gulf, Red Sea, Egypt. Egyptian Journal of Aquatic Biology \& Fisheries, 24(6): 425-434.

Minghelli-Roman, A.; Chisholm, J. R.; Marchioretti, M. and Jaubert, J. M. (2002). Discrimination of coral reflectance spectra in the Red Sea. Coral Reefs, 21(3): 307314.

Mona, M. H.; El-Naggar, H. A.; El-Gayar, E. E.; Masood, M. F. and Mohamed, E. N. E. (2019). Effect of human activities on biodiversity in Nabq Protected Area, South Sinai, Egypt. Egypt. J. of Aquat. Res., 45: 33-43.

Mumby, P. J.; Green, E. P.; Clark, C. D. and Edwards, A. J. (1998). Digital analysis of multispectral airborne imagery of coral reefs. Coral Reefs, 17: 59-69.

PERSGA/GEF. (2003). Regional Action Programme for the Conservation of Coral Reefs in the Red Sea and Gulf of Aden. PERSGA Technical Series No. 3. PERSGA, Jeddah. (English).

Purkis, S. J. and Pasterkamp, R. (2004). Integrating in situ reef-top reflectance spectra with Landsat TM imagery to aid shallow-tropical benthic habitat mapping. Coral Reefs, 23: 5-20.

Rasaiah, B. A.; Bellman, C.; Jones, S. D.; Malthus, T. J. and Roelfsema, C. (2015). Towards an Interoperable Field Spectroscopy Metadata Standard with Extended Support for Marine Specific Applications. Remote Sens., 7: 15668-15701.

Richards, J. A. (1999). Remote Sensing Digital Image Analysis: An Introduction, Springer-Verlag, Berlin, Germany.

Rowlands, G. P.; Purkis, S. J. and Riegl, B. M. (2008). The 2005 coral-bleaching event Roatan (Honduras): use of pseudo-invariant features (PIFs) in satellite assessments. J Spatial Sci 53(1): 99-112. 
Shaban, W.; Abdel-Gaid, S. E.; El-Naggar, H. A.; Bashar, M. A.; Masood, M.; Salem, E. S. and Alabssawy, A. N. (2020). Effects of recreational diving and snorkeling on the distribution andabundance of surgeonfishes in the Egyptian Red Sea northern islands. Egypt. J. Aquat. Res., 46(3): 251-257.

Swift, S. A. and Bower, A. S. (2003). "Formation and Circulation of Dense Water in the Persian/Arabian Gulf.'Journal of Geophysical Research: Oceans, 108 (C1).

Thomas, I. L.; Benning, V. M. and Ching, N. P. (1987). Classification of remotelysensed images. Adam Hilger, Bristol.

Valentine, P. C.; Todd, B. J. and Kostylev, V. E. (2005). "Classification of Marine Sublittoral Habitats with Application to the Northeastern North America Region."American Fisheries Society Symposium, Bethesda, Maryland, 41: 183-200.

White, J. and Fitzpatrick, F. (2007). "How Do I Collect My Sata?" MESH Guide to Habitat Mapping. MESH Project, 2007, JNCC, Peterborough.

Williams, S.; Pizarro, O.; Jakuba, M. and Barrett, N. (2010). AUV Benthic Habitat Mapping in South Eastern Tasmania. In "Field and Service Robotics" Howard, A., Iagnemma, K. \& Kelly, A. (Eds.) Springer Verlag, Germany, 62: 275-84. doi:10.1007/978-3-642-13408-1_25.

Yamano, H.; Shimazaki, H.; Matsunaga, T.; Ishoda, A.; McClennen, C.; Yokoki, H.; Fujita, K.; Osawa, Y. and Kayanne, H. (2006). Evaluation of various satellite sensors for waterline extraction in a coralreef environment: Majuro Atoll, Marshall Islands. Geomorphology, 82: 398-411.

Zakaria H. Y. and El-Naggar H. A. (2019). Long-term variations of zooplankton community in Lake Edku, Egypt. Egypt. J. Aquat. Biol. Fish., 23(4): 215-226.

Zakaria, H. Y.; Hassan, A. M.; El-Naggar, H. A. and Abou-Senna, F.M. (2016). Abundance, distribution, diversity and zoogeography of epipelagic copepods off the Egyptian Coast (Mediterranean Sea). Egypt. J. Aquat. Res., 42(4): 459-473

Zakaria, H. Y.; Hassan, A. M.; El-Naggar, H. A. and Abou-Senna, F. M. (2018a). Biomass determination based on the individual volume of the dominant copepod species in the Western Egyptian Mediterranean Coast. Egypt. J. Aquat. Res., 44: 8999.

Zakaria, H. Y.; Hassan, A. M.; El-Naggar, H. A. and Abou-Senna, F. M. (2018b). Planktonic protozoan population in the Southeastern Mediterranean off Egypt. Egypt. J. Aquat. Res., 44: 101-107.

Zakaria, H. Y.; El-Kafrawy, S. B. and El-Naggar, H. A. (2019). Remote Sensing Technique for Assessment of Zooplankton Community in Lake Mariout, Egypt. Egypt. J. Aquat. Biol. Fish., 23(3): 599-609. 